\title{
Efektivitas Perendaman Tangan Kaki dengan Air dan Pengolesan Campuran VCO dan Olive Oil dalam Mengatasi Efek Samping Kemoterapi (Palmar-Plantar Erythorodysesthesia) pada Pasien Kanker Kolon di Murni Teguh Memorial Hospital
}

\author{
Seriga Banjarnahor ${ }^{\mathrm{a}^{*}}$, Harsudianto Silaen ${ }^{\mathrm{b}}$ \\ STIKes Murni Teguh,Medan 20236, Indonesia \\ abanjarnahorseraiaga@gmail.com*, bwshbsr@yahoo.com \\ * corresponding author
}

\section{ARTICLE INFO}

Keywords

Immersion Hand Feet with Water VCO and Olive Oil Mixing

Chemotherapy

Palmar-Plantar Erythrodysesthesia

\begin{abstract}
Patients with colon cancer undergoing chemotherapy at the Pure Teguh Memorial Hospital both inpatient and outpatient experience many Palmar-Plantar Erythrodysesthesia. Palmar-Plantar Erythrodysesthesia incident that occurs in colon cancer patients due to side effects of chemotherapy. The high incidence of Plamr-Plantar Erythrodysesthesia in colon cancer patients is related to the lack of immersion of the feet with water and the application of a misture of VCO and olive oil. This type of research is a quasy experimental study of post test only non eguivalent control group design that aims to determine the effectiveness of soaking the foot with water and applying a mixture of $\mathrm{VCO}$ and Olive Oil in overcoming the side effects of chemotherapy (PalmarPlantar Erythrodysesthesia) in colon cancer patients in Pure Teguh Memorial Hospital.The population in this study were all colon cancer patients who were undergoing chemotherapy in the Murni Teguh Memorial hospital chemotherapy center as many as 90 patients and a sample of 90 patients consisting of 45 people in the intervention group and 45 in the control group). Data were analyzed with chi square test. The results of the study are the effectiveness of foot immersion soaking with water and the application of a mixture of VCO and olive oil to overcome the side effects of chemotherapy (Palmar-Plantar Erythrodysesthesia) in colon cancer patients at Murni Teguh Memorial Hospital.As a suggestion in this study, it is expected that immersion of foot hands with water and the application of a mixture of VCO and olive oil to reduce Palmar-Plantar Erythrodysesthesia in colon cancer patients at Murni Teguh Memorial Hospital and for patients should immerse foot hands with water and basting mixture of VCO olive oil data to reduce the incidence of Palmar-Plantar Erythrodysesthesia.
\end{abstract}

\section{Pendahuluan}

Kanker adalah pertumbungan sel-sel baru secara tidak normal yang tumbuh melampaui batas normal, dan selanjutnya dapat menyerang bagian tubuh dan menyebar ke organ lainnya dinamakan metastasis [1]. Kanker kolon adalah suatu penyakit keganasan yang terjadi dipermukaan usus besar yang ditandai dengan munculnya jaringan epithel abnormal pada kolon. Kanker kolon merupakan penyakit keganasan nomor tiga terbanyak di dunia dan penyebab kematian kedua terbanyak di Amerika Serikat [2]. Di Indonesia kanker kolon merupakan urutan nomor tiga yaitu 
12,8 per 100.000 penduduk dewasa dengan mortalis 9,5\% dari seluruh kasus kanker. Hasil survei awal Jumlah pasien kanker kolon yang dilayani pada kemoterapi center di Murni Teguh Memorial Hospital rawat inap maupun rawat jalan sebanyak 956 pasien pada tahun 2017 [3].

Penatalaksanaan kanker kolon menurut pedoman nasional pelayanan kedokteran kolorektal Depkes RI tahun 2017, pada stadium II, III dan IV adalah reseksi tumor primer pada kasus kanker kolon dengan metastasis yang dapat direseksi dan kemoterapi sistemik pada kasus kanker kolon dengan metastasis yang tidak dapat direseksi dan tanpa gejala. Terapi sistemik kemoterapi tersebut dengan pemberian obat kemoterapi sesuai denganstadium kankernya. Obat kemoterapi yang diberikan berdasarkan pertimbangan seperti Flourourasit salah satu efek pemberian obat ini adalah sindrom palmar-plantar erythrodysesthesia atau hand-food syundrome, dan Capecitabine mempunyai efek samping yang sering timbul adalah sindrom palmar-plantar erythrodysesthesia atau hand-food syundrome [5] [6] [7].

Efek samping kemoterapi yang ditimbulkan karena obat-obatan kemoterapi tersebut tidak hanya menghancurkan sel-sel kanker tetapi juga menghacurkan sel-sel sehat khususnya sel-sel yang membelah dengan cepat sehingga membuat sel-sel sehat mengalami kerusakan yang berakibat fatal dalam kehidupan pasien kemoterapi diantaranya rambut rontok, mual muntah, diare dan konstipasi, masalah kulit (palmar-plantar erythrodisthesia), anemia, infeksi dan lain-lain. Efek samping dari pelaksanaan kemoterapi itu sendiri yaitu masalah kulit (palmar-plantar erythrodisthesia) dapat ditangani dengan cara perendaman tangan kaki dengan air dan pengolesan campuran Olive Oil dan Virgin Coconut Oil (VCO) setiap hari selama menjalani kemoterapi [8].

Beberapa pasien yang menjalani kemoterapi dengan diagnose kanker kolon tidak mengalami efek samping yang bermakna maka dilakukan wawancara lansung pasien tersebut melakukan perendaman pada tangan dan kaki dengan air dan mengoleskan campuran olive oil dan $V C O[9]$.

\section{Metode}

Jenis penelitian ini merupakan penelitian Quasy Eksperimen post test only non eguivalent control group design.bertujuan untuk mengetahui hubungan sebab akibat dan mencari pengaruh dari satu intervensi terhadap populasi.

Lokasi penelitian ini dilakukan di Murni Teguh Memorial Hospital dengan pertimbangan Murni Teguh Memorial Hospital merupakan salah satu rumah sakit rujuikan pasien kanker yang memiliki fasilitas yang memadai serta memiliki kemoterapi terpadu, adanya beberapa pasien kanker kolon yang sedang mendapat terapi kemoterapi dengan menggunakan perendaman air dan pengolesan ilive oil dan $V C O$. Waktu penelitian dilaksanakan mulai April sampai November Tahun 2019.

Populasi dalam penelitian ini adalah seluruh pasien kanker kolon yang sedang menjalani kemoterapi di ruang kemoterapi center Murni Teguh Memorial hospital. Sampel penelitian ini yakni seluruh polpulasi dijadikan menjadi yaitu sebanyak 90 orang pasien (dimana ada 45 orang yang kelompok intervensi dan 45 orang kelompok kontrol) dalam waktu 2 bulan.

Penelitian ini dimulai dari survey pendahuluan pengajuan surat permohonan izin pelaksanaan penelitian pada Stikes Murni Teguh Medan Program S1 keperawatan setelah disetujui maka selanjutnya mengajukan permohonan izin penelitian ke Murni Teguh Memorial Hospital, peneliti mengumpulkan data yang diperoleh secara langsung dari responden dengan tehnik wawancara yang berpedoman pada kuesioner yang dibagikan pada responden. Pengumpulan data terdiri dari 16 item pertanyaan dengan nilai jawaban ya $=1$ dan tidak $=0$. Data yang telah dikumpulkan dan dilengkapi dianalisa dengan uji chi square pada tingkat kepercayaan $95 \%(\alpha=0,05)$ [10].

\section{Hasil dan Diskusi} Analisa Univariat

Tabel 1.Distribusi Frekuensi Efek Samping Kemoterapi

(Palmar-Plantar Erythrodysesthesia) pada Pasien Kanker Kolon pada Kelompok Intervensi

\begin{tabular}{lcc}
$\begin{array}{l}\text { Kejadian (Palmar-Plantar } \\
\text { Erythrodysesthesia) }\end{array}$ & $\mathrm{f}$ & $\%$ \\
\hline Mengalami & 7 & 15,6 \\
Tidak Mengalami & 38 & 84,4 \\
\hline \multicolumn{1}{c}{ Total } & $\mathbf{4 5}$ & $\mathbf{1 0 0 , 0}$ \\
\hline
\end{tabular}


Berdasarkan tabel 1, diketahui bahwa pasien kanker kolon yang menjalani kemoterapi di Murni Teguh Memorial Hospital menggunakan perendaman tangan kaki dengan air dan Pengolesan Campuran VCOdanOlive Oil lebih banyak mengalami Palmar-Plantar Erythrodysesthesia sebanyak 38 orang $(84,4 \%)$ dan lebih sedikit dengan tidak mengalami PalmarPlantar Erythrodysesthesia sebanyak 7 orang $(15,6 \%)$.

Tabel 2.Distribusi Frekuensi Efek Samping Kemoterapi (Palmar-Plantar Erythrodysesthesia) pada Pasien Kanker Kolon pada Kelompok Kontrol

\begin{tabular}{lcc}
\hline $\begin{array}{l}\text { Kejadian (Palmar-Plantar } \\
\text { Erythrodysesthesia) }\end{array}$ & F & \% \\
\hline Mengalami & 28 & 62,2 \\
Tidak Mengalami & 17 & 37,8 \\
\hline \multicolumn{1}{c}{ Total } & $\mathbf{4 5}$ & $\mathbf{1 0 0 , 0}$ \\
\hline
\end{tabular}

Berdasarkan tabel 2, diketahui bahwa pasien kanker kolon yang menjalani kemoterapi di Murni Teguh Memorial Hospital tidak menggunakan perendaman tangan kaki dengan air dan Pengolesan Campuran VCO danOlive Oil lebih banyak mengalami Palmar-Plantar Erythrodysesthesia sebanyak 28 orang $(62,2 \%)$ dan lebih sedikit dengan tidak mengalami sebanyak 17 orang $(37,8 \%)$.

\section{Hasil Penelitian}

Analisa Bivariat

Tabel 3. Silang (Crosstab) Efektifitas Perendaman Tangan Kaki dengan Air dan Pengolesan Campuran VCO dan Olive Oil dalam Mengatasi Efek Samping Kemoterapi (Palmar-Plantar Erythrodysesthesia) pada Pasien Kanker Kolon

\begin{tabular}{|c|c|c|c|c|c|c|c|c|}
\hline \multirow[t]{3}{*}{ No } & \multirow{3}{*}{$\begin{array}{l}\text { Rendam Tangan Kaki dengan } \\
\text { Air dan Pengolesan Campura } \\
V C O \text { dan Olive Oil }\end{array}$} & \multicolumn{4}{|c|}{$\begin{array}{l}\text { Palmar-Plantar } \\
\text { Erythrodysesthesia }\end{array}$} & \multirow{2}{*}{\multicolumn{2}{|c|}{ Total }} & \multirow[t]{3}{*}{$\begin{array}{c}p \\
\text { value }\end{array}$} \\
\hline & & \multicolumn{2}{|c|}{ Mengalami } & \multicolumn{2}{|c|}{$\begin{array}{c}\text { Tidak } \\
\text { Mengalami }\end{array}$} & & & \\
\hline & & f & $\%$ & $\mathbf{f}$ & $\%$ & $\mathbf{f}$ & $\%$ & \\
\hline 1 & Memberikan & 7 & 15,6 & 38 & 84,4 & 45 & 100 & 0,000 \\
\hline 2 & Tidak Memberikan & 28 & 62,2 & 17 & 37,8 & 45 & 100 & \\
\hline
\end{tabular}

Berdasarkan tabel 3, diketahui bahwa dari 45 pasien kanker kolon pada kelompok intervensi yang menjalani kemoterapi di Murni Teguh Memorial Hospital mengalami PalmarPlantar Erythrodysesthesia sebanyak 7 orang $(15,6 \%)$ dan tidak mengalami Palmar-Plantar Erythrodysesthesia sebanyak 38 orang $(84,4 \%)$. Dari 45 pasien kanker kolon pada kelompok kontrol yang menjalani kemoterapi di Murni Teguh Memorial Hospital mengalami Palmar-Plantar Erythrodysesthesiasebanyak 28 orang $(62,2 \%)$ dan tidak mengalami Palmar-Plantar Erythrodysesthesiasebanyak 17 orang $(37,8 \%)$.

Kemudian berdasarkan hasil uji chi square diperoleh bahwa $\mathrm{p}$ value $=0,000<\alpha=0,05$ artinya ho ditolak artinya ada Efektifitas Perendaman Tangan Kaki dengan Airdan Pengolesan Campuran VCO danOlive Oil dalam Mengatasi Efek Samping Kemoterapi(Palmar-Plantar Erythrodysesthesia) pada Pasien Kanker Kolon di RS Murni Teguh Memorial Hospital.

\section{Pembahasan}

1. Efektifitas Perendaman Tangan Kaki dengan Air dan Pengolesan Campuran VCO Data Olive Oil dalam Mengatasi Efek Samping Kemoterapi (Palmar-Plantar Erythrodysesthesia) pada Pasien Kanker Kolon

Hasil penelitian diperoleh bahwa pasien kanker kolon yang menjalani kemoterapi di RS Murni Teguh Memorial Hospital dengan menggunakan perendaman tangan kaki dengan air dan Pengolesan Campuran VCO danOlive Oil lebih banyak tidak mengalami Palmar-Plantar 
Erythrodysesthesias sebesar 84,4\%, sedangkan pasien yang tidak menggunakan perendaman tangan kaki dengan air dan Pengolesan Campuran VCO danOlive Oil lebih banyak mengalami Palmar-Plantar Erythrodysesthesias sebesar 62,2\% [11] [12] [13]

Kemudian berdasarkan hasil uji chi square diperoleh bahwa $p$ value $=0,000<\alpha=0,05$ artinya ho ditolak artinya ada Efektifitas Perendaman Tangan Kaki dengan Air dalam Mengatasi Efek Samping Kemoterapi(Palmar-Plantar Erythrodysesthesia) pada Pasien Kanker Kolon di Murni Teguh Memorial Hospital.

Mengacu pada hasil uji statistik tersebut bahwa semakin dilakukan Perendaman Tangan Kaki dengan Air dan Pengolesan Campuran VCO danOlive Oilakan semakin mengatasi efek samping kemoterapi (Palmar-Plantar Erythrodysesthesia) pada Pasien Kanker Kolon dan sebalinya semakin tidak dilakukan Perendaman Tangan Kaki dengan Air dan Pengolesan Campuran VCO danOlive Oilpada pasien kanker kolon menjalani kemoterapi akan semakin meningkatkanefek samping kemoterapi (Palmar-Plantar Erythrodysesthesia) pada Pasien Kanker Kolon.

Kemoterapi banyak dikenal sebagai metode pengobatan kankeryang menggunakan obat-obatan khusus guna membunuh sel-sel kanker yang bersarang di dalam tubuh. Penggunaan obat-obatan ini yang sering kali menyebabkan efek samping pada pengidapnya yang meliputi mual, muntah, kelelahan, rambut rontok, perubahan pada kulit, nafsu makan menurun, penurunan memori, perubahan emosional, masalah kesuburan, dan lain sebagainya [14]

Efek samping dari kemoterapi ini tentunya tidak selalu sama pada setiap orang. Seorang terkena kanker kolom bisa saja mengalamiPalmar-Plantar Erythrodysesthesiausai menjalani kemoterapi, sementara efek samping yang muncul pada pasien lainnya mungkin tidak terlalu parah. Sebenarnya, efek samping kemoterapi tidak selalu seburuk. Prosesnya, pertumbuhan sel-sel kanker yang tergolong cepat, sehingga obat-obatan kemoterapi juga harus bekerja ekstra untuk membunuh perkembangan sel kanker. Namun, karena obat-obatan ini menyebar ke seluruh bagian tubuh, maka bisa dengan mudah memengaruhi organ dan sel-sel lainnya yang masih normal dan sehat.

Itu sebabnya, organ dan sel-sel lain yang terserang dampak kemoterapi secara berangsur-angsur akan melemah dan rusak hingga akhirnya menimbulkan efek samping. Beberapa sel normal yang bisa rusak akibat kemoterapi seperti Palmar-Plantar Erythrodysesthesia.

Menurut Maryunani (2013) bahwa Perendaman Kaki Tangan dan Kaki dengan menggunakan Air bertujuan untuk mempertahankan Moist atau kelembapan luka tersebut sehingga penyembuhan luka serta penyerapan terhadap obat topical lebih cepat . Perendaman tangan kaki yang dilakukan dalam penelitian ini berlangsung secara kontiniu selama dua jam perhari sebelum tidur[3] [15].

Menurut Alleyman (2013) bahwa manfaat dari olive oil tersebut memegang peranan penting dalam kesehatan yang kaya akan antioksidan ( $\alpha$ tokoferol) untuk melindungi kesehatan kulit dan mencegah pertumbuhan sel kanker. Manfaat lainnya menjaga kelenturan kolagen kulit serta mengadung asam laurat dan oleat yang bersifat melembutkan kulit. Sehingga meningkatkan permeabilitas kulit serta menjaga elastisitas kulit [4].

\section{Kesimpulan}

Pasien kanker kolon yang menjalani kemoterapi diMurni Teguh Memorial Hospital dengan menggunakan perendaman tangan kaki dengan air dan Pengolesan Campuran VCO danOlive Oil lebih banyak tidak mengalami Palmar-Plantar Erythrodysesthesias sebesar 86,5\%

Pasien kanker kolon yang menjalani kemoterapi di Murni Teguh Memorial Hospital dengan tidak menggunakan perendaman tangan kaki dengan air dan Pengolesan Campuran VCO danOlive Oil lebih banyak mengalami Palmar-Plantar Erythrodysesthesias sebesar 60,5\%.

Terdapat Efektifitas Perendaman Tangan Kaki dengan Airdan Pengolesan Campuran VCO danOlive Oil dalam Mengatasi Efek Samping Kemoterapi(Palmar-Plantar Erythrodysesthesia) pada Pasien Kanker Kolon diMurni Teguh Memorial Hospital.

\section{Referensi}

[1] Black, J.M, Hawks J.H.(2006).Medical Surgical Nursing, Clinical Management for Positive Outcomes ( $8^{\text {th }}$ Edition), Philadelpia. WB. Saunders Company.

[2] Capecitabine Per Oral Dilihat Dari Skor Kualitas Hidup Dan Derajat Hand Foot Syndrome.Jurnal Kedokteran Diponegoro.Volume 7(4).ISSN Online : 2540-8844 
[3] Martschick A, Sehouli J, Patzelt A, Richter H, Jacobi U, Oskay-Ozcelik G, Sterry W, Lademann J.(2009).The pathogenetic mechanism of anthracycline-induced palmarplantar erythrodysesthesia.Anticancer Res. Vol 29(6):2307-13.

[4] Riani, F.H.Perbandingan Efektivitas Perawatan Luka Modern "Moist Wound Healing" Dan Terapi Komplementer "Nacl 0,9\% + Madu Asli" Terhadap Penyembuhan Luka Kakidiabetik Derajat Ii Di Rsud Bangkinang.(2017). Jurnal Ners Universitas Pahlawan. Vol 1, No 2.ISSN 2580-2194

[5] Tanasale M.L.P.(2013).“Aplikasi Starter Ragi Tape Terhadap Rendemen dan Mutu Virgin Coconut Oil (VCO)", Vol 02, No. 01, Fakultas Pertanian Universitas patimura Ambon.

[6] Putra. M, Yan Wisnu Prajoko, Selamat Budijitno.(2018).Efektivitas Virgin Coconut Oil Dalam Penanganan Hand Foot Syndrome Pada Pasien Kanker Payudara Yang Mendapat Kemoterapi Capecitabine Per Oral Dilihat Dari Skor Kualitas Hidup Dan Derajat Hand Foot Syndrome.Jurnal Kedokteran Diponegoro.Volume 7(4).ISSN Online : 2540-8844.

[7] Alleyman, G.(2013). Health Benefit of Olive Oil: Inflamation Benefit from Olive Oil. Diakses 15 April 2019.

[8] Batros M, Kozody LL, Orsted HL.(2008). Preventative Foot Care. Wound Care Canada.Vol $6(1)$.

[9] Chan, Huan-Keat \& Ismail, S. (2014). Side Effect of Chemotherapy among Cancer Patients in a Malaysian General Hospital: Experiences, Perceptions and informationalNeeds from Clinical Pharmacists. Asian Pacific Journal of Cancer Prevention.15, 5305- 5309.

[10] Cancer.Net Editorial Board.(2017).Hand-Foot Syndrome or Palmar-Plantar Erythrodysesthesia.https://www.cancer.net/coping-with-cancer/physical-emotionalandsocial-effects-cancer/managing-physical-side-effects/hand-foot-syndrome-orpalmarplantar-erythrodysesthesia. Diakses pada Tanggal 08 Mei 2018.

[11] Maryunani, Anik.(2013). Perawatan Luka (Modern Wound care) Terlengkap dan Terkini.Jakarta: In Media.

[12] Putra. M, Yan Wisnu Prajoko, Selamat Budijitno.(2018).Efektivitas Virgin Coconut Oil Dalam Penanganan Hand Foot Syndrome Pada Pasien Kanker Payudara Yang Mendapat Kemoterapi

[13] Intahphuak S, Khonsung P, Panthong A. 2010. Anti-inflammatory, analgesic, and antipyretic activities of virgin coconut oil. Pharmaceutical biology;48:151-7.

[14] G. Nevin TR. 2010.Effect of Topical Application of Virgin Coconut Oil on Skin Components and Antioxidant Status during Dermal Wound Healing in Young Rats US National Library of Medicine.

[15] Wood, J.L.\& Heber, J. (2014). Nursing research methodes and critical appraisal for evidence-based practice. 8th Edition. St.Louis : Mosby Elsevier. 